\section{A PROSPECTIVE STUDY ON THE EFFECT OF THE BELSEY MARK IV 270-DEGREE FUNDOPLICATION ON LOWER ESOPHAGEAL SPHINCTER CHARACTERISTICS AND ESOPHAGEAL BODY MOTILITY}

The effect of the Belsey Mark IV operation on lower esophageal sphincter characteristics and esophageal body motor function was prospectively studied in $\mathbf{3 8}$ patients who underwent successful operation (relief of symptoms, healing of esophagitis; group I) and 8 who had surgical failure (group II). Mean follow-up was 3 years ( 0.5 to 8 years). Only in group $I$ a rise in basal lower esophageal sphincter pressure (from $8.3 \pm 0.8 \mathrm{~mm} \mathrm{Hg}$ to $14.5 \pm 0.5 \mathrm{~mm} \mathrm{Hg}, p<0.001$ ), total sphincter length (from $2.7 \pm 0.1 \mathrm{~cm}$ to $3.4 \pm 0.1 \mathrm{~cm}, p<0.001$ ), and the intraabdominal sphincter segment $(1.3 \pm 0.1 \mathrm{~cm}$ to $2.3 \pm 0.1 \mathrm{~cm}, p<0.001)$ with a reduction of the intrathoracic segment (from $1.5 \pm 0.1 \mathrm{~cm}$ to $1.1 \pm 0.1 \mathrm{~cm}, p<0.05$ ) was recorded. Preoperative and postoperative lower esophageal sphincter pressure and length values showed a large overlap. Antireflux operation had no effect on peristaltic amplitude, velocity, and duration, irrespective of the outcome of operation. One of five patients with incomplete swallow-induced lower esophageal sphincter relaxation had moderate dysphagia. Successful operation by 270-degree fundoplication is accompanied by a significant increase in lower esophageal sphincter pressure and length and does not affect esophageal body motor function. (J THORAC CARDIOvaSC SURG 1995;109:636-41)

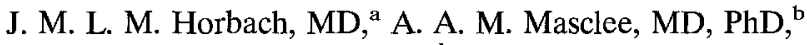

C. B. H. W. Lamers, MD, PhD, ${ }^{\mathrm{b}}$ and H. G. Gooszen, $\mathrm{MD}, \mathrm{PhD},{ }^{\mathrm{a}}$

Leiden, The Netherlands
A ntireflux operation is an adequate method of controlling gastroesophageal reflux disease (GERD) in patients whose condition is resistant to current medical treatment. ${ }^{1-4}$ There is an ongoing debate, however, about the changes brought about by and functional implications of such an operation. ${ }^{5}$ More recently insights into the pathophysiologic mechanisms have extended dramatically. ${ }^{6}$ Several reports have been written on the effects of 360-degree fundoplication on lower esophageal sphincter (LES) characteristics and esophageal body motility. 7,8 However, little is known about the changes brought about by partial ( 270 degree) fundoplication. This prospective study focuses on the effects of the Belsey Mark IV (270-degree fundoplication) antireflux procedure on LES features and

From the Departments of Surgery ${ }^{\mathrm{a}}$ and Gastroenterology and

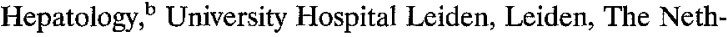
erlands.

Received for publication Feb. 16, 1994.

Accepted for publication Sept. 30, 1994.

Address for correspondence: H. G. Gooszen, MD, Department of Surgery, University Hospital Utrecht, P.O. Box 85500, 3508 GA Utrecht, The Netherlands.

Copyright (C) 1995 by Mosby-Year Book, Inc.

$0022-5223 / 95 \$ 3.00+0 \quad \mathbf{1 2 / 1 / 6 1 0 2 8}$ esophageal motility. To evaluate the clinical importance of these changes, the data obtained in patients who underwent successful operation were compared with those of patients who had clinical and objective (endoscopy) failure of treatment.

\section{Material and methods}

Forty-six nonconsecutive patients who had undergone a Belsey Mark IV procedure between 1981 and 1992 were studied. Patients were included in this study only if the complete set of data on clinical history, upper gastrointestinal tract endoscopy, and manometry was availabie.

The group consisted of 38 patients who underwent successful operation (group I) and 8 who had failed operation (group II). Successful antireflux operation was defined as the combination of the absence or major improvement of reflux symptoms (no medical treatment required) with the absence of esophagitis at endoscopy. The group consisted of 22 male and 24 female patients, with a median age of 49 years (range 25 to 75 ).

Persistence or deterioration of esophagitis and/or symptoms of GERD despite medical treatment of at least 6 months' duration was the indication for surgical treatment in all cases. Medical treatment consisted of $\mathrm{H}_{2}$ receptor antagonists as monotherapy or in combination with mucosal protecting agents and prokinetic drugs. Dietary and postural guidelines were given in addition. Beginning in 1989 proton-pump inhibitors were included in the medical treatment and operation was done after recurrence of severe symptoms when acid-suppression was tapered to maintenance dosages. 
Table I. Symptom scoring system for combined scoring of severity and frequency of GERD symptoms

\begin{tabular}{lcccc} 
& \multicolumn{4}{c}{ Severity } \\
\cline { 2 - 5 } \multicolumn{1}{c}{ Frequency } & Severe & Moderate & Mild & Absent \\
\hline Daily & Grade 3 & Grade 2 & Grade 1 & - \\
Once a week & Grade 2 & Grade 1 & Grade 1 & - \\
Once a month & Grade 1 & Grade 1 & Grade 1 & - \\
Less frequently & Grade 1 & Grade 1 & Grade 1 & - \\
\hline
\end{tabular}

The diagnosis of GERD was based on the combination of reflux symptoms (retrosternal pain, heartburn, regurgitation, and dysphagia), endoscopic findings, and 24-hour $\mathrm{pH}$ measurement.

A contrast $\mathrm{x}$-ray film of the esophagus was taken on the seventh postoperative day in all cases to document the correct position of the esophagogastric junction below the diaphragm and to confirm the absence of contrast reflux.

The mean period of follow-up was 3 years (range 0.5 to 8 ). Follow-up time for both groups (success, failure) was not different.

Symptoms were scored according to a system that combined frequency and severity of the symptom, as described earlier (Table I). ${ }^{9}$ Dysphagia was studied separately in relation to effect of operation and incomplete relaxation after operation. During endoscopy, the severity of esophagitis was graded according to the criteria of Savary and Miller.

Manometry. Tests for lower esophageal sphincter pressure (LESP), sphincter length, and esophageal body motility were done after an overnight fast. A small polyvinyl four-lumen composite side-hole catheter was used. The orifices were placed $5 \mathrm{~cm}$ apart and oriented radially at 90 degrees to each other. Each lumen was perfused with distilled water with a low-compliance pneumohydraulic capillary perfusion pump (Arndorfer Medical Specialties, Greendale, Wis.). After transnasal passage the recording catheter was positioned in the stomach. Thereafter the catheter was withdrawn into the esophagus by a stationary pull-through technique at $0.5 \mathrm{~cm}$ intervals. LESP was the mean of four end-expiratory LESP values measured in each channel, with end-expiratory gastric baseline pressure serving as zero reference point.

Intraluminal esophageal pressures were recorded at 5 , 10,15 , and $20 \mathrm{~cm}$ above the upper margin of the LES. The manometric responses to 15 standardized wet swallows (10 $\mathrm{ml}$ water bolus) were recorded. Peristaltic wave amplitude and duration of contraction were calculated for the proximal ( 20 to $15 \mathrm{~cm}$ above the LES), middle (15 to $10 \mathrm{~cm}$ above the LES), and distal $(10$ to $5 \mathrm{~cm}$ above the LES) parts of the esophagus. Velocity of peristalsis for the proximal, middle, and distal parts of the esophagus was calculated from the time of onset between peristaltic wave peaks between adjacent transducers. It was measured over three intervals of $5 \mathrm{~cm}$ in the proximal (20 to $15 \mathrm{~cm}$ above the LES), middle (15 to $10 \mathrm{~cm}$ above LES), and distal $(5 \mathrm{~cm}$ above the LES) parts of the esophagus.

Statistical analysis. Paired Wilcoxon signed-rank test was used for all paired samples and Mann-Whitney test
Table II. Endoscopic grade of esophagitis before and after operation in patients with successful and failed operation

\begin{tabular}{lccccc}
\hline & \multicolumn{2}{c}{$\begin{array}{c}\text { Successful } \\
(n=38)\end{array}$} & & \multicolumn{2}{c}{$\begin{array}{c}\text { Failed } \\
(n=8)\end{array}$} \\
\cline { 2 - 3 } \cline { 5 - 6 } Grade & Before & After & & Before & After \\
\hline 0 & 9 & 38 & & 2 \\
I & 11 & - & & 2 & 1 \\
II & 14 & - & & 3 & 5 \\
III & 3 & - & & - \\
IV & 1 & - & & 1 & - \\
\hline
\end{tabular}

Table III. LES pressure and length before and after operation in patients with successful and failed operation

\begin{tabular}{lccccc}
\hline & \multicolumn{2}{c}{ Successful $(n=38)$} & & \multicolumn{2}{c}{ Failed $(n=8)$} \\
\cline { 2 - 3 } \cline { 5 - 6 } & Before & After & & Before & After \\
\hline LESP (mm Hg) & $8.3 \pm 0.8$ & $14.5 \pm 0.5^{*}$ & & $5.7 \pm 1.1$ & $8.3 \pm 0.9 \dagger$ \\
Length LES (cm) & & & & \\
$\quad$ Total & $2.7 \pm 0.1$ & $3.4 \pm 0.1^{*}$ & $3.0 \pm 0.2$ & $2.8 \pm 0.2 \dagger$ \\
Intrathoracic & $1.5 \pm 0.1$ & $1.1 \pm 0.1 \ddagger$ & & $1.6 \pm 0.1$ & $1.1 \pm 0.1$ \\
Intraabdominal & $1.3 \pm 0.1$ & $2.3 \pm 0.1^{*}$ & & $1.4 \pm 0.2$ & $1.7 \pm 0.2 \S$
\end{tabular}

Results expressed as mean plus or minus standard error of mean. Total, Total length of high-pressure zone; Intrathoracic, length of high-pressure zone above respiratory inversion point; Intraabdominal, length of highpressure zone below respiratory inversion point.

${ }^{*} p<0.001$ after operation versus before operation.

$\dagger p<0.01$ success versus failure after operation.

$\ddagger p<0.01$ after operation versus before operation.

$\$ p<0.05$ success versus failure after operation.

for unpaired data. Spearman's rank correlation was used to analyze LESP and total and intraabdominal highpressure segment. The level of significance was $p<0.05$.

\section{Results}

Effect of operation on endoscopic findings. Table II shows the results of esophagoscopy before and after operation in both groups. Although 9 of the 38 patients in the successful group had no signs of esophagitis before operation, the patients had documented reflux disease with abnormal 24-hour $\mathrm{pH}$ values. None of the 38 patients from group I had any signs of esophagitis after the operation. In group II, operation had no effect on endoscopic findings, apart from one patient whose condition improved from grade IV to grade II esophagitis.

Effect of operation on LES characteristics. No differences in LES function parameters between group I and II were observed before operation (Table III). LESP and sphincter length values (total, intrathoracic, and intraabdominal) all fell in the same range. After antireflux operation, a significant 


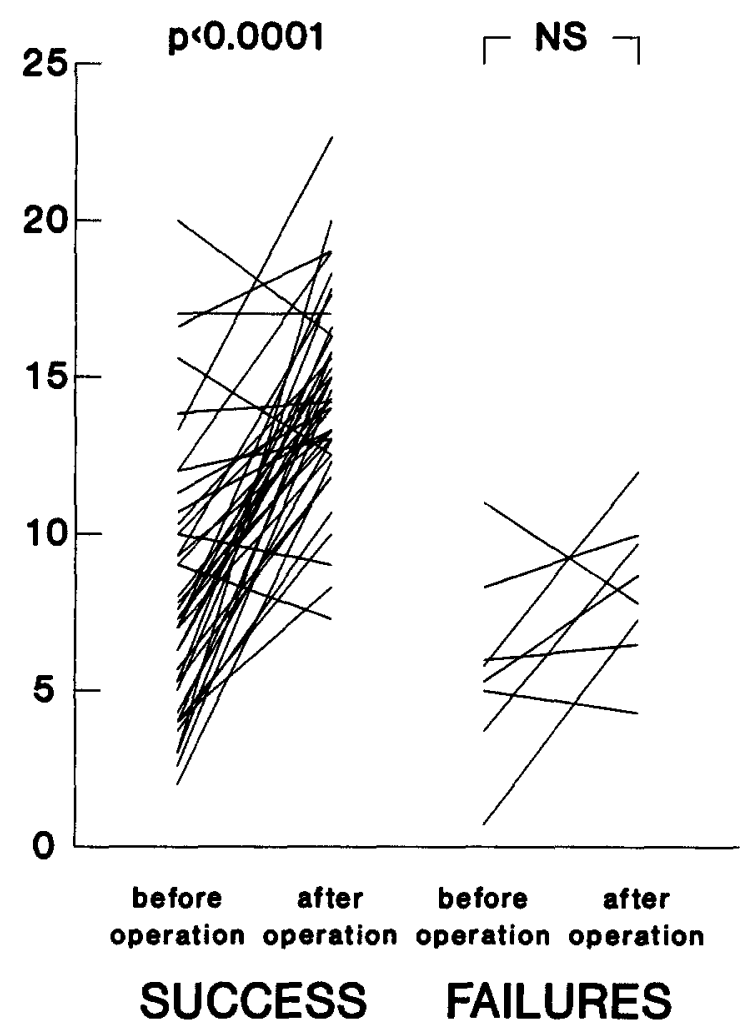

Fig. 1. Effect of Belsey Mark IV operation on basal LESP in millimeters of mercury ( $y$ axis) in group of patients who had successful operations $(n=38, p<$ 0.0001 , left panel) and group of patients with surgical failure ( $n=8$, right panel). Successful operation is defined as relief of symptoms with healing of esophagitis. Mark the considerable overlap between preoperative and postoperative basal LESP values in both groups. NS, Not significant.

rise in LESP from $8.3 \pm 0.8 \mathrm{~mm} \mathrm{Hg}$ to $14.5 \pm 0.5$ $\mathrm{mm} \mathrm{Hg}$ was observed in group I $(p<0.0001)$. In four patients (4 of 38 ) operation was successful although LESP decreased after operation. In group II, LESP was not significantly influenced by operation $(5.7 \pm 1.1 \mathrm{~mm} \mathrm{Hg}$ to $8.3 \pm 0.9 \mathrm{~mm} \mathrm{Hg})$. Postoperative LESP values in group I were significantly higher than those in group II $(p<0.01)$ (Fig. 1 ), although there was some overlap for four of the eight patients in group II.

In group I, the total length of the high-pressure zone $(2.7 \pm 0.1 \mathrm{~cm}$ to $3.4 \pm 0.1 \mathrm{~cm}, p<0.0001$; Fig. 2 ) and the length of the intraabdominal segment $(1.3 \pm 0.1 \mathrm{~cm}$ to $2.3 \pm 0.1 \mathrm{~cm}, p<0.0001)$ both increased, whereas the intrathoracic segment (1.5 \pm $0.1 \mathrm{~cm}$ to $1.1 \pm 0.1 \mathrm{~cm}, p<0.01$ ) decreased. In group II, no significant change was observed in intraabdominal segment, intrathoracic segment, or

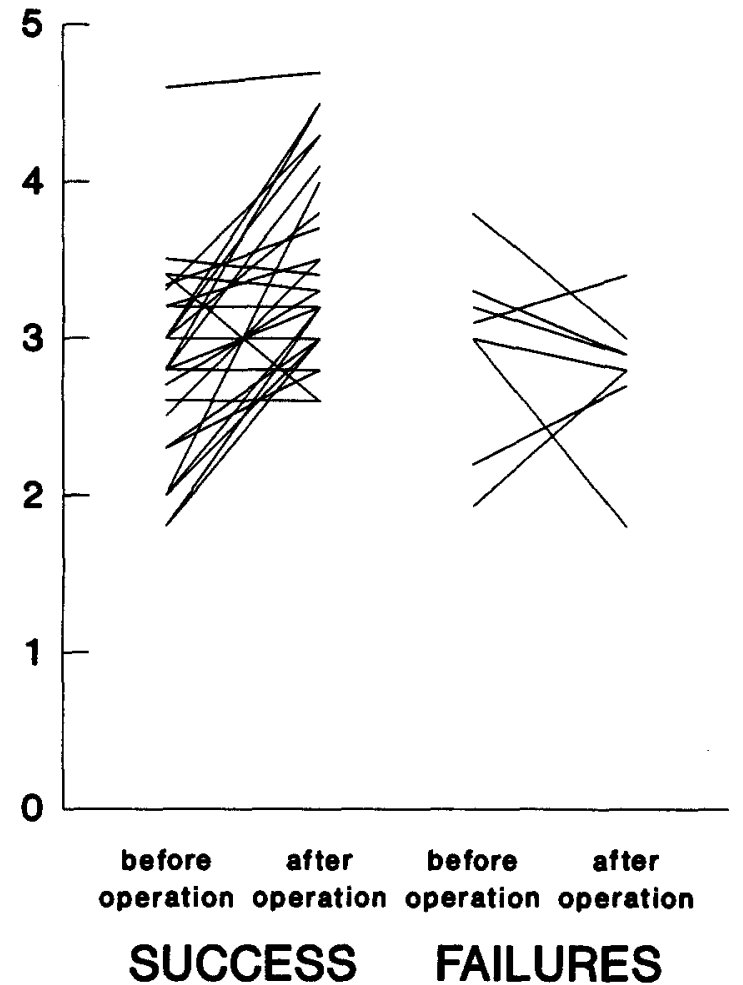

Fig. 2. Preoperative and postoperative length of LES in centimeters ( $y$ axis) in group of patients who had successful operations (left panel, $n=38, p<0.0001$ ) and group of patients with surgical failure (right panel, $n=8$ ). Successful operation is defined as relief of symptoms with healing of esophagitis. Note almost complete overlap between both groups.

total length of the high-pressure zone after antireflux operation. Differences between both groups were also found with respect to postoperative values for total length $(p<0.01)$ and intraabdominal segment $(p<0.05)$, which were significantly lower after operation in group II (Table III).

The LESP and intraabdominal segment before $(r=0.39, p<0.05)$ and after $(r=0.45, p<0.01)$ operation for the whole group of 46 patients did not show a high degree of correlation (Fig. 3), which indicated that a postoperative increase in pressure was usually accompanied by an increase in length, but not to a similar extent.

Incomplete relaxation of the LES during swallowing was observed in 5 of all 46 patients after operation. One patient (with a basal LESP of $14 \mathrm{~mm}$ $\mathrm{Hg}$ ) had moderate, but not troublesome, dysphagia. Gas-bloat syndrome was not seen.

Dysphagia was present before operation in 15 patients (10 mild, 3 moderate, and 2 severe). Disap- 

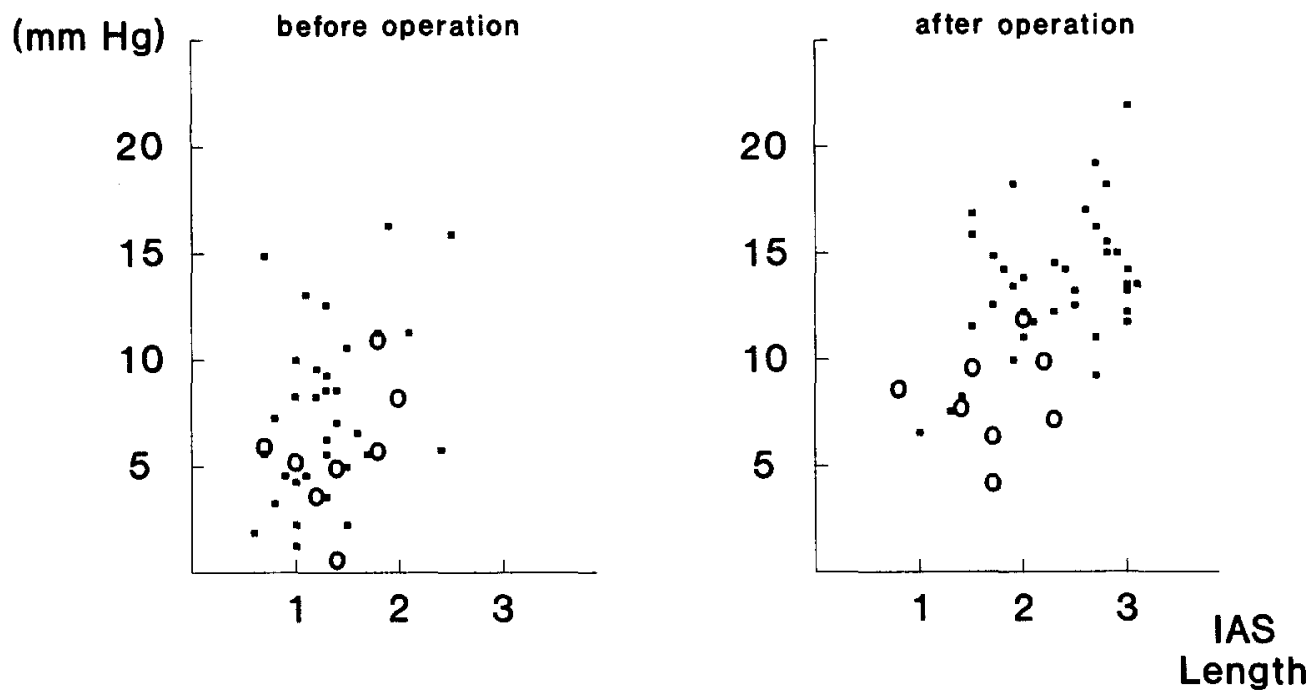

Fig. 3. Correlation between length in centimeters ( $x$ axis) and pressure in millimeters of mercury ( $y$ axis) of LES before (left panel) and after (right panel) antireflux operation. Patients who had successful operations $(n=38)$ are indicated as black dots and those with surgical failure as open circles. Surgical success is defined as relief of symptoms with healing of esophagitis. $I A S$, Intraabdominal segment.

pearance of dysphagia or major improvement was established in 5 patients, whereas in 8 it did not change (6 mild and 2 moderate). Dysphagia developed in 2 of the patients without dysphagia before operation (both moderate) $(N=23)$, and no postoperative dysphagia was observed in the other 21 patients. One of the two patients with operationinduced dysphagia had incomplete relaxations of the LES during swallowing. No correlation was found between LESP and dysphagia either before or after operation.

Effect of operation on esophageal motility. Table IV describes the effects of 270 -degree fundoplication on esophageal motility. Partial fundoplication did not affect any esophageal motility parameter studied (amplitude, velocity, or duration of contractions), irrespective of the outcome of surgical treatment.

\section{Discussion}

This prospective study shows that the Belsey Mark IV operation leads to an increase in LESP, total length of the LES, and length of the intraabdominal segment. It remains unclear, however, which of these features is the main determinant of success, defined as symptomatic relief and endoscopic healing. Previously, the operation-induced rise in LESP has been called the main factor in controlling reflux. This has been supported by so-
Table IV. Amplitude, velocity, and duration of contractions before and after operation in patients with successful and failed operations

\begin{tabular}{lcclll}
\hline & \multicolumn{2}{c}{ Successful $(N=38)$} & & \multicolumn{2}{c}{ Failed $(N=8)$} \\
\cline { 5 - 6 } & Before & After & & Before & After \\
\hline Amplitude (mm Hg) & & & & \\
$\quad$ Proximal & $43 \pm 2$ & $43 \pm 2$ & & $37 \pm 6$ & $39 \pm 4$ \\
$\quad$ Middle & $40 \pm 2$ & $37 \pm 2$ & & $40 \pm 6$ & $33 \pm 5$ \\
$\quad$ Distal & $42 \pm 2$ & $45 \pm 2$ & & $37 \pm 5$ & $33 \pm 4$ \\
Velocity (cm/sec) & & & & \\
$\quad$ Proximal & $3.5 \pm 0.2$ & $3.3 \pm 0.2$ & $3.6 \pm 0.5$ & $3.0 \pm 0.4$ \\
$\quad$ Distal & $4.2 \pm 0.2$ & $4.0 \pm 0.2$ & $3.6 \pm 0.5$ & $3.4 \pm 0.4$ \\
Duration (sec) & & & & \\
$\quad$ Proximal & $2.4 \pm 0.1$ & $2.6 \pm 0.1$ & $2.7 \pm 0.1$ & $2.7 \pm 0.1$ \\
$\quad$ Distal & $3.2 \pm 0.1$ & $3.2 \pm 0.1$ & $3.2 \pm 0.1$ & $2.9 \pm 0.2$
\end{tabular}

Results expressed as mean plus or minus standard error of mean. No significant differences before and after operation or between success and failure were observed. Proximal, Proximal part of esophagus; Middle, middle part of esophagus; Distal, distal part of esophagus.

phisticated evaluation of sphincter function and even by using three-dimensional profiles. ${ }^{10-12}$

In this study successful operation was accompanied by a basal LESP of greater than $8 \mathrm{~mm} \mathrm{Hg}$. However, six of the eight patients who were scored as having failed operations also had postoperative basal pressures of greater than $8 \mathrm{~mm} \mathrm{Hg}$. Moreover, half of the patients with GERD had a basal LESP of greater than $8 \mathrm{~mm} \mathrm{Hg}$ before operation. Thus the role of basal LESP in controlling reflux as an 
isolated phenomenon seems limited. Sphincter pressure and length are significantly related but not with a high degree of correlation, and in looking at length as a denominator for success there is even a larger overlap between "success" and "failure." The same holds true for the length of the intraabdominal segment. Thus both sphincter length and pressure seem to be of limited importance in controlling GERD.

Both sphincter pressure and length can be calibrated during operation and on the basis of the findings of this study a sphincter length of greater than $3.5 \mathrm{~cm}$ (the highest length measured after failed operation) should be strived for. This figure supports the work of O'Sullivan and associates ${ }^{11}$ and Joelson, DeMeester, and Skinner ${ }^{13}$ in the early 1980 s in which they showed that a LES of greater than $3 \mathrm{~cm}$ in length leads to $90 \%$ competence of the cardia. The data on intraoperative manometry are conflicting. Orringer, Schneider, and Williams ${ }^{14}$ have stressed the debatable predictive value with respect to postoperative basal sphincter pressure, whereas $\mathrm{Hill}^{15}$ greatly relies on intraoperative sphincter pressure calibration to tailor the antireflux procedure. Although the predictive value for the outcome of operation is limited, attention should be paid to the length of the fundoplication, because this is easily done and our data support the relevance. Techniques of sphincter pressure calibration with a sleeve catheter may prove to be helpful in the prevention of recurrent pathologic reflux after operation.

It must be emphasized that creating a highpressure zone and an intraabdominal segment is not a goal in itself, but is an accompanying phenomenon of the aim to restore the anatomic defect and to thus create some sort of flap valve by fixing the stomach to the esophagus over an arbitrary length between 3 and $5 \mathrm{~cm}$, without tension, to prevent the tearing out of the 270-degree fundoplication sutures. A basal LESP of $8 \mathrm{~mm} \mathrm{Hg}$ or higher is observed in all patients who have undergone successful operation in terms of resolution of symptoms and esophagitis. In another study we observed that complete control of reflux, as assessed by 24-hour $\mathrm{pH}$ measurement, was found in all patients with a postoperative basal LESP greater than $15 \mathrm{~mm} \mathrm{Hg}$. In that study, patients who had no symptoms with a basal LESP between 8 and $15 \mathrm{~mm} \mathrm{Hg}$ did not have esophagitis, but reflux as assessed by 24-hour $\mathrm{pH}$ measurement did not completely normalize. ${ }^{16}$ In this study, we found no significant difference in total and intraabdominal sphincter length between the 9 patients with a basal LESP of greater than $15 \mathrm{~mm} \mathrm{Hg}$ and the 29 patients who had lower basal LESP. Therefore basal pressure rise should be an important goal to aim for to fully normalize the 24-hour $\mathrm{pH}$ profile. However, if antireflux operation aims at increasing basal LESP to greater than $15 \mathrm{~mm} \mathrm{Hg}$ there may be the risk of creating a supercompetent valve with the induction of dysphagia or gas bloat. We have observed moderate operation-induced dysphagia in one patient who otherwise had a successful operation. Incomplete swallow-induced relaxation of the sphincter was observed in this patient, and four other patients had similar absence of swallow-induced relaxations, without obstructive symptoms. Therefore, although basal LESP is increased as part of successful antireflux operation, there does not seem to be a critical upper and lower limit to aim between.

Incomplete relaxation of the LES after wet swallowing is a recently recognized accompanying phenomenon of a 360-degree wrap procedure. ${ }^{17}$ The clinical relevance and possible relation to postoperative dysphagia are as yet unknown. In this study incomplete sphincter relaxation was observed in only $11 \%$ of all patients who underwent operation. Indirect evidence for the relation between degree of fundoplication, LES relaxation, and dysphagia is presented by Thor and Silander ${ }^{18}$ in their prospective randomized study comparing a 360-degree with an 180-degree fundic wrap. They reported less dysphagia after partial fundoplication with a similar rise in basal LESP and the same effectiveness (symptom relief, healing of esophagitis) as that obtained after a complete wrap.

Recently some authors have shown that not only basal LESP rises, but also that changes in esophageal motility are observed. ${ }^{8,19,20}$ After antireflux operation these investigators describe a postoperative rise in amplitude, peristaltic velocity, and duration of contractions. ${ }^{7}$ Values are in the same range as observed in normal control subjects in their study. We have observed no changes in esophageal body motility after antireflux operation, irrespective of the outcome of the operation or of the presence of esophagitis before operation. We believe that our data are corroborated by the observation that no changes in esophageal body motility were observed after successful treatment and healing of esophagitis with omeprazole. ${ }^{21}$ Thus we do not believe that a rise in amplitude, peristaltic velocity, and duration is necessarily part of successful treatment. Perhaps the observed increase in esophageal body motility parameters indicates that a 360 -degree fundoplication in- 
duces a barrier at the level of the LES with a reactive increase in peristaltic activity to overcome this barrier. This suggestion is supported by the correlation between high sphincter pressure and dysphagia as a postoperative symptom in that study.

We conclude that successful antireflux operation is characterized by a significant rise in basal LESP with a concomitant but not proportional rise in total and intraabdominal sphincter length. Changes in esophageal body motor function are not part of successful antireflux operation. Preoperative LESP is neither useful in selecting candidates for operation nor in predicting surgical outcome. Apparently other aspects of LES and esophageal function play an additional and important role in determining the result of antireflux operation.

\section{REFERENCES}

1. Skinner DB, Belsey RHR, Russell PS. Surgical management of esophageal reflux and hiatus hernia. Long-term results with 1,030 patients. J Cardiovasc Surg 1964;53:33-54.

2. Spechler SJ. Comparison of medical and surgical therapy for complicated gastroesophageal reflux disease in veterans. N Engl J Med 1992;326:787-92.

3. Johnsson F, Joelsson B, Gudmundson K, Florén CH, Walther B. Effects of fundoplication on antireflux mechanism. Br J Surg 1987;74:1111-4.

4. Alday ES, Goldschmidt HS. Efficacy of fundoplication in preventing gastric reflux. Am J Surg 1973;126: 322-7.

5. Jamieson GG. Anti-reflux operations: how do they work? Br J Surg 1987;74:155-6.

6. Dent J, Holloway RH, Toouli J, Dodds WJ. Mechanisms of lower oesophageal sphincter incompetence in patients with symptomatic gastroesophageal reflux. Gut 1988;29:1020-8.

7. Martinez de Haro L, Parrilla Paricio P, Ortiz Escandell MA, et al. Antireflux mechanism of Nissen fundoplication: a manometric study. Scand J Gastroenterol 1992;27:417-20.

8. Gill RC, Bowes KL, Murphy PD, Kingma YJ. Esophageal motor abnormalities in gastroesophageal reflux and the effects of fundoplication. Gastroenterology 1986;91:364-9.
9. Horbach JMLM, Cnossen MH, Jansen JBMJ, et al. A prospective study on the effects of Belsey Mark IV antireflux surgery on endoscopic esophagitis, lower esophageal sphincter pressure and $24 \mathrm{hr} \mathrm{pH}$ monitoring: relation to symptom improvement. Dig Dis Sci 1994;39:385-92.

10. Henderson RD. Gastroesophageal junction in hiatus hernia. Can J Surg 1972;15:63-72.

11. O'Sullivan GC, DeMeester TR, Joelsson BE, et al. The interaction of the lower esophageal sphincter pressure and length of sphincter in the abdomen as determinants of gastroesophageal competence. Am J Surg 1982;143:40-7.

12. Stein HJ, DeMeester TR, Naspetti R, Jamieson J, Perry RE. Three-dimensional imaging of the lower esophageal sphincter in gastroesophageal reflux disease. Ann Surg 1991;214:374-84.

13. Joelson BE, DeMeester TR, Skinner DB. The role of the esophageal body in the antireflux mechanism. Surgery 1982;92:417-22.

14. Orringer MB, Schneider R, Williams GW. Intraoperative esophageal manometry: is it valid? Ann Thorac Surg 1980;30:13-8.

15. Hill LD. Intraoperative measurement of lower esophageal sphincter pressure. J THORAC CARDIOVASC SURG 1978; $75: 378-82$.

16. Horbach JMLM, Masclee AAM, Lamers CBHW, Gooszen HG. Prospective evaluation of 24 hour ambulatory $\mathrm{pH}$ metry in Belsey Mark IV antireflux surgery. Gut 1994;35:1529-36.

17. Ireland AC, Holloway RH, Toouli J, Dent J. Mechanisms underlying the antireflux action of fundoplication. Gut 1993;34:303-8.

18. Thor KBA, Silander T. A long-term randomized prospective trial of the Nissen procedure versus a modified Toupet technique. Ann Surg 1989;210:719-24.

19. Bancewicz J, Mughal M, Marples M. The lower oesophageal sphincter after floppy Nissen fundoplication. Br J Surg 1987;74:162-4.

20. Ortiz Escandell A, Martinez de Haro LF, Parrilla Paricio P, Aguayo Albasini JL, Garcia Marcilla JA, Morales Cuenca G. Surgery improves defective oesophageal peristalsis in patients with gastroesophageal reflux. Br J Surg 1991;78:1095-7.

21. Singh $\mathrm{P}$, Adamopoulos A, Taylor RH, Colin-Jones DG. Oesophageal motor function before and after healing of oesophagitis. Gut 1992;33:1590-6. 